\title{
The current practice of mentoring across Accreditation Council of Graduate Medical Education - International accredited programs in Qatar from faculty and trainees perspectives
}

This article was published in the following Dove Press journal:

Advances in Medical Education and Practice

\author{
Shireen Suliman' \\ Ahmed Al-Mohammed' \\ Dabia Al Mohanadi' \\ Margaret Allen ${ }^{2}$ \\ Carma L Bylund ${ }^{2}$ \\ 'Department of Internal Medicine, \\ ${ }^{2}$ Department of Medical Education, \\ Hamad Medical Corporation, Doha, \\ Qatar
}

\begin{abstract}
Purpose: Mentoring plays a vital role in academic productivity, personal development, and career guidance for students, residents, fellows, and junior faculty. A culture of mentoring is spreading across residency and fellowship training programs in Hamad Medical Corporation, the main teaching tertiary care facility in Qatar. However, there is insufficient knowledge about the current practice of mentoring in these programs.
\end{abstract}

Methods: We conducted a cross-sectional study by surveying all faculty and trainees in all residency and fellowship training programs in Qatar. Each completed a web-based questionnaire that asked about the current experience, self-efficacy and measures of improvement of the current practice of mentoring across training programs.

Results: A total of 393/650 faculty members (61\%), 187/250 fellows (74\%), and 405/650 residents (62\%) responded to the two surveys. Most (74\% of faculty members) reported being current mentors, while $67 \%$ of residents and fellows reported that they currently have mentors. Faculty who received training in mentoring and those who had an established formal mentoring program in their departments were more likely to enroll in mentoring than others $(86 \%, P<0.01$; $71 \%, P<0.05 \%$, respectively). Trainees suggested that the two main areas to improve the current mentoring initiative in their departments were to develop a structured mentoring program and to train the mentors. Content analysis revealed participants' confusion differentiating between the terms mentoring and supervision.

Conclusion: Based on the current study, many existing mentoring relationships have an evident confusion between supervision and mentoring roles. Developing structured mentoring program and training both faculty and trainees in mentoring is recommended to improve the current practice of mentoring within the training programs.

Keywords: ACGME-I, Accreditation Council of Graduate Medical Education-International, supervision, faculty development, residency program, fellowship program

\section{Introduction}

Throughout history, mentors have played a significant role in teaching, supporting, and developing the skills and talents of others. ${ }^{1}$ To date, mentoring has been widely studied within academic medicine, ${ }^{2-4}$ where it is perceived to play an important role in influencing personal development, career guidance, career choice and success, and research productivity. Mentoring has been defined traditionally as a dyadic relationship in which the more experienced mentor helped guide the career of a younger organizational member as this protégé learned to "navigate the world of work". 5 Despite considerable evidence establishing the positive benefit of mentoring across a range of 
domains, medicine as a profession has been slow to introduce formal mentoring programs (FMP). ${ }^{6}$

Residency training is a period of remarkable professional growth and meaningful personal development, as young physicians acquire clinical and professional skills that will help shape their future career and build (or weaken) important personal relationships. ${ }^{7}$ Residency is associated with burnout and stress due to many factors such as relocation, separation from friends, and long hours, which contribute to an increased risk of depressive symptoms that impact patient care and personal health. ${ }^{8-11}$ Medical schools and residency and fellowship programs are charged with training health care professionals and with advancing clinical care, research, and education. ${ }^{12,13}$ Moreover, mentors develop their own skills such as leadership capacity through mentoring others and their performance gains from job-related support received from protégés. ${ }^{14}$ The benefits experienced by the mentee and mentors collectively provide advantages to the organization, resulting in more faculty who are highly productive, creative, satisfied, and committed to their organizations. ${ }^{15}$

Following Accreditation Council of Graduate Medical Education - International (ACGME-I) implementation at our institution, an increasing number of residency and fellowship training programs in Qatar are creating the necessity to integrate mentoring into these programs. Program directors are aware of the benefits of mentoring and are working to establish such initiatives. However, insufficient knowledge about the current practice of mentoring is hindering successful practice. The aim of this study is to examine the current mentoring practice in Qatar (as a multinational country with a dominance of Arab culture among these training programs) and identify anticipated barriers, and measures of improvement from both faculty and trainees' perspectives. This may provide a guide for the development of FMP.

\section{Methods}

\section{Participants and setting}

Hamad Medical Corporation (HMC) is a Joint Commission International (JCI) accredited teaching secondary and tertiary care institute and the sole institution that provides fellowship and residency training programs across Qatar. It has 12 hospitals that are considered training sites. The residency training programs and several fellowship programs at HMC have been accredited by the ACGME-I.

All faculty, fellows, and residents at HMC were invited to participate in an online survey in June 2016. Potential participants received an email invitation from the authors to participate in the study, followed by 3 reminder emails over the period of 11 days. Participants completed web-based questionnaires (trainees 21 items and faculty 18 items) about their current experience, their self-efficacy, and measures of improvement of the current practice of mentoring across training programs at HMC. Participation was voluntary and anonymous.

The surveys were piloted among experts in medical education (faculty survey) and a group of residents and fellows (trainees' survey) to ensure face and content validity. The questionnaires included Likert-scaled questions about the faculty understanding and both past and current experience in mentoring and trainees' current experience with mentoring and satisfaction. A mentor was defined at the beginning of the survey as a trusted and experienced advisor who has a direct interest in the development and education of another individual. ${ }^{16}$ There were also 4 open-ended questions at the end of the questionnaires that invited free responses and comments on the current practice of mentoring, any suggestions for improvement, together with the anticipated barriers and benefits of introducing mentoring programs within the training programs.

The study was approved by the Institution's Research Board at HMC and completion of the survey was deemed as consent to participate through the utilization of a simple consent paragraph that was provided by Medical Research Center at HMC in an approval letter.

\section{Data analysis}

Statistical analysis was carried out using the software package SPSS 22.0 (SPSS Inc., Chicago, IL, USA). We calculated the mean of all the variables and used unpaired $t$-tests to analyze the quantitative variables means between faculty training and provision of formal mentoring with the current practice of mentoring.

\section{Results}

\section{Response rate and respondents' demographic data}

Five hundred and ninety-two trainees of 900 (65\%) responded to our survey, 405/650 (70\%) were residents and 187/250 $(75 \%)$ were clinical fellows. Among faculty the highest response rate was from medicine, surgery, anesthesia and radiology respectively. Amongst trainees, medicine, pediatrics, anesthesia and obstetrics and gynecology returned a higher response. The characteristics of the respondents are reported in Table 1.

\section{Faculty mentors and trainees as mentees}

Table 2 displays the characteristics of current mentoring experiences from both faculty and trainees' perspectives. When it 
Table I Demographic data of the respondents

\begin{tabular}{llllll}
\hline Demographic data of the respondents & & & & \\
\hline Faculty & $\mathbf{n}(\%)$ & Fellows & n (\%) & Residents & n (\%) \\
\hline Senior consultants & $202(5 \mathrm{I})$ & Year I & $59(34)$ & PGYI & $95(24)$ \\
Consultants & $191(49)$ & Year 2 & $46(26)$ & PGY2 & $78(20)$ \\
& & Year 3 & $45(26)$ & PGY3 & $103(27)$ \\
& & Year 4 & $25(14)$ & PGY4 & $70(18)$ \\
& & & PGY5 & $42(11)$ \\
\hline Completed the survey & $393 / 650(61)$ & & & $405 / 650(70)$ \\
\hline
\end{tabular}

Abbreviation: PGY, post graduate year.

Table 2 Characteristics of mentoring experience

\begin{tabular}{|c|c|c|}
\hline & \multicolumn{2}{|c|}{ Mentoring practice } \\
\hline & $\begin{array}{l}\text { Faculty } \\
\text { mentors } \\
\text { n (\%) }\end{array}$ & $\begin{array}{l}\text { Trainee } \\
\text { mentees } \\
\text { n (\%) }\end{array}$ \\
\hline \multicolumn{3}{|l|}{ Current mentor/mentees } \\
\hline Current mentor & $281 / 379(74)$ & - \\
\hline Have mentors & & $387(67)$ \\
\hline No mentor & & $128(22)$ \\
\hline Do not know & & $62(11)$ \\
\hline Residents & $213(76)$ & - \\
\hline Fellows & $127(45)$ & - \\
\hline Junior faculty & $75(27)$ & - \\
\hline Other & $39(14)$ & - \\
\hline Mentors assigned by department & & $247(64)$ \\
\hline Self-appointed mentors & & II7 (3I) \\
\hline \multicolumn{3}{|l|}{ Mentoring relationship } \\
\hline Formal & $169(61)$ & $228(60)$ \\
\hline Informal & $109(48)$ & $124(35)$ \\
\hline \multicolumn{3}{|l|}{ Meetings } \\
\hline Monthly & $|3|(48)$ & $99(26)$ \\
\hline Quarterly & 147 (I7) & $64(17)$ \\
\hline Biannually & $35(13)$ & $101(27)$ \\
\hline Annually & $9(3)$ & $32(8)$ \\
\hline Never met & $3(1)$ & $10(3)$ \\
\hline Other (weekly/daily) & $50(18)$ & $71(18)$ \\
\hline \multicolumn{3}{|l|}{ Training in mentoring } \\
\hline Received & $168(49)$ & - \\
\hline Not received & $\mid 72(5 \mid)$ & - \\
\hline \multicolumn{3}{|l|}{$\begin{array}{l}\text { Existence of formal mentoring } \\
\text { program }\end{array}$} \\
\hline Present & $229(68)$ & 274 (49) \\
\hline Absent & $110(32)$ & $117(21)$ \\
\hline Do not know & 0 & $164(30)$ \\
\hline
\end{tabular}

comes to assessing the faculty self-reflection on frequency of demonstrating mentoring skills in a scale of $1-5$ (where 1 is never and 5 is always) they rated themselves high, between 4 and 5 . Faculty rated their overall quality in mentoring as high with scores of $5(16 \%), 4(62 \%), 3(20 \%), 2$ (2\%), and $1(0 \%)$. Table 3 demonstrates faculty mentoring skills form both faculty and trainees' perspectives.

We compared faculty who are currently mentors with those who are not. Eighty six percent of faculty who received training on mentoring are currently mentors while only $62 \%$ of those who have not received training are current mentors reflecting a significant $P<0.001 ; 71 \%$ of the current mentors have an established FMP in their department while only $29 \%$ of faculty are mentors despite their departments not providing formal mentoring $(P \leq 0.05 \%)$.

\section{Faculty non-mentors and trainees' non-mentees}

In open ended questions, faculty who were not mentors identified three main factors that led to lack of engagement which were: 1) the time factor and the workload, 2) lack of FMP, and 3) lack of official assignments by their program leaders. All faculty rated mentoring as an essential element in the career development of trainees. Also $98 \%$ (50\% as very important and $36 \%$ as important, $12 \%$ as somewhat important) identified the importance of being mentored to their own career development.

Among trainees who are not mentored, $83 \%$ of trainees believe they will benefit from FMP as it will result in a better training program in the form of identifying the program objectives, enhancing both academic and research in the training program, and finally improving resident/faculty relationships and the working environment of individual mentees.

\section{Benefits and barriers from both faculty and trainees' perspectives}

Among faculty who do not currently have an FMP, 91\% recommended introducing FMP in their department. Perceived barriers suggested by the faculty include lack of time, lack of incentives, lack of culture, possible personal conflicts, lack of role models, communication problems, unstructured approaches to mentoring, and lack of space. Thus, their suggestions on improving the current mentoring practice in their departments were categorized into four domains as shown in Table 4. Ninety one percent of all respondents were interested in participation in a mentoring training program. 
Table 3 Residents versus faculty perceived mentoring skills

\begin{tabular}{|c|c|c|c|}
\hline Mentoring skill & $\begin{array}{l}\text { Faculty perception } \\
\text { (mean } \pm S D)\end{array}$ & $\begin{array}{l}\text { Resident perception } \\
\text { (mean } \pm \text { SD) }\end{array}$ & P-value \\
\hline I communicate regularly with my mentee(s) & $4.10 \pm 0.823$ & $3.08 \pm 0.81$ & 0.001 \\
\hline Use of different styles of communication & $3.93 \pm 0.93$ & $3.03 \pm 0.746$ & 0.001 \\
\hline Establishment of a relationship based on trust & $4.50 \pm 0.74$ & $3.29 \pm 0.742$ & 0.001 \\
\hline Setting clear expectations of mentoring relationship & $4.12 \pm 0.935$ & $2.92 \pm 0.842$ & 0.001 \\
\hline Contribution to professional development mentees & $4.25 \pm 0.829$ & $3.08 \pm 0.768$ & 0.001 \\
\hline Provision of motivation to mentees & $4.42 \pm 0.686$ & $3.13 \pm 0.794$ & 0.001 \\
\hline Support of personal development of mentees & $4.39 \pm 0.761$ & $3.10 \pm 0.814$ & 0.001 \\
\hline Aiding mentees in making career decisions & $4.07 \pm 0.884$ & $2.93 \pm 0.815$ & 0.001 \\
\hline Provision of advice regarding clinical skills & $4.46 \pm 0.771$ & $3.14 \pm 0.763$ & 0.001 \\
\hline Guidance of mentees to develop research & $3.73 \pm 1.112$ & $2.84 \pm 0.839$ & 0.001 \\
\hline Supporting the educational experience of mentees & $4.33 \pm 0.79$ & $3.14 \pm 0.757$ & 0.001 \\
\hline
\end{tabular}

Table 4 Faculty/trainee perceived barriers to successful mentoring relationship and suggestions for improvement

\begin{tabular}{lll}
\hline Factors & Barriers to mentoring & Suggestion for improvement \\
\hline Trainees' factors & Time factor and workload & Commitment \\
Pentors & Workload & $\begin{array}{l}\text { Provide feedback to faculty } \\
\text { Provide training }\end{array}$ \\
& Lack of motivation & Provision of protected time \\
Rrogram leaders & Conflict of supervisory and mentoring roles & Develop structured MP \\
& Lack of structured program & Follow-up and monitoring \\
& Lack of space for mentoring meetings & Faculty appreciation \\
& & Engage all faculty \\
Mentoring relationship & Lack of communication & Proper match system \\
& No clear goals and objectives & Scheduled meetings \\
& Lack of proper selection criteria & Clear objectives and goals
\end{tabular}

\section{Discussion}

\section{Mentoring practice and misconception}

In academic medicine, mentoring is recognized as a crucial developmental relationship. ${ }^{17}$ Our study revealed that faculty values the benefits of mentoring as an essential element in the career development of trainees and their own career development. According to Douglas ${ }^{18}$ and Allen et al, ${ }^{19}$ mentoring results in increased confidence, personal fulfilment, and assistance on projects. Mentoring has an important influence on personal development, career guidance, career choice, and research productivity ${ }^{20}$ also, according to Scott, ${ }^{21}$ it involves a helping relationship, emotional support, personal interaction, and role modeling. These ideas were expressed in the comments by our faculty.

Our study has shown good numbers of faculty enrolled in mentoring (74\%) and existence of FMP (68\%) within the training programs. In spite of that, questions regarding the exact mentoring relationship revealed confusion between the mentoring and the supervisor roles among trainees. Exploring further the existence of FMP and the mentoring relationship, around one third of trainees stated that they meet their mentors on daily, weekly, or twice a week basis expressing that their mentors are their direct supervisors and they provide them with frequent feedback in the workplace. This lack of clarity has consequences in practice-oriented disciplines, where the development of programs is based on assumptions about the meaning and effectiveness of mentoring., ${ }^{1,22}$ Therefore, there should be a clear definition of mentoring shared with all participants. Mentoring relationships should have clear outcomes such as publications, promotions, etc, that are continuously assessed in order to make improvements.

Faculty provides trainees supervision according to JCI standards. Supervision is defined as the provision of monitoring, guidance, and feedback on matters of personal, professional, and educational development in the context of patient care. The main purpose of supervision is insurance of both trainees and patient safety. Residents who were more closely supervised during continuity clinical experience gained primary care skills more rapidly than those who were supervised by reporting back to the physician. ${ }^{23}$ According 
to Urish, ${ }^{24}$ the terms "mentoring" and "supervision" are not synonymous but are often used interchangeably. The primary focus of supervision is accountability for the supervisee's performance (e.g., providing grades or conducting performance evaluations; documenting professional behavior and clinical performance) while mentoring focuses on creating effective ways to build skills, influence attitudes, and cultivate aspirations. ${ }^{25}$ While mentoring nurtures trainees' professional development, the ultimate purpose of supervision, whether stated or implied, is to improve patient care. ${ }^{26}$

\section{Identified barriers}

Both the faculty and the trainees identified obstacles that would act as potential impediments to the development of a successful mentoring relationship. Those are summarized into four points from both faculty and trainees' perspectives in Table 2. Time factor and busy schedules are the major identified barriers. This has been also demonstrated by Straus et al who identified the amount of time spent by both the mentor and mentee to be the single most important barrier to mentorship. ${ }^{27}$ Both faculty and trainees admitted a lack of mentoring skills or formal training program where faculty had only experientially learned about mentoring. The third factor is resistance to new culture as faculty might resist the suggestion that they have anything new to learn about mentoring. Faculty commented "Change in culture is needed and critical mass of interested staff". Finally, lack of academic recognition for mentors and the perception that mentors' work was not recognized was highlighted by many faculty.

\section{Suggestions for improving mentoring}

The following themes emerged: 1) developing structured mentoring program with follow-up and monitoring by the program leaders. Seventy one percent of the current mentors have an established FMP in their department while only $29 \%$ of faculty are mentors if their department has not provided formal mentoring $(P<0.05 \%)$. This reflects the need for program support at various levels; the importance of mentor training; the careful selection of participants; and the need for ongoing evaluations. ${ }^{1}$ 2) Providing training to faculty and trainees in mentoring and developing FMP within the fellowship and residency programs are the pillars of successful mentoring relationships. ${ }^{28}$ Our study had shown a significant correlation of $(P<0.01)$ value between faculty training and enrollment in mentoring relationship. While faculties demonstrated higher self-perception of mentoring skill, mentees perception scored lower with significant $P$-value $<0.001$. This substantial difference in the perceptions demonstrated in Table 3 can be attributable to the lack of awareness of the exact differences between faculty supervisory and mentoring roles among trainees and therefore their expectations, lack of appreciation from mentee's side or possibly lack of faculty mentoring skills. Whether they are current mentors or not, $91 \%$ of our faculty were interested in participating in a mentoring training program with a need for more focus on communication and research skills as underscored by faculty. Administrators responsible for establishing mentoring programs should consider maximizing the experience of mentoring for all stakeholders. ${ }^{29} 3$ ) Faculties should be provided with support in order to enhance their value of mentoring by giving them incentives such as protected time and awards. ${ }^{28,30}$ Successful mentoring requires commitment and interpersonal skills of the mentor and mentee, but also a facilitating environment at academic medicine institutions. ${ }^{31}$

Finally, our study resulted in increasing the awareness of the concept at our institution and of many program directors who demonstrated intentions to develop and train their faculty on skills of effective mentoring relationships.

\section{Conclusion}

While our study demonstrated a good number of mentoring relationships currently in place at our institution, many points need to be addressed; confusion between supervision and mentoring; a clear message from both the faculty and trainees of the need to develop FMP within both fellowship and residency training programs; and the many anticipated benefits and challenges for developing FMP. Educating faculty and trainees on the concepts of mentoring, engaging program leaders to initiate and monitor FMP with well-established outcomes and overcome any barriers were the main suggestions for disseminating a structured and true culture of mentoring across the training programs.

\section{Acknowledgment}

The authors should like to acknowledge Dr Abdullatif Al-Khal, Deputy Chief of Medical, Academic and Research Affairs, and Office of Chief at Hamad Medical Corporation for his support in initiation of the mentoring program at HMC.

\section{Disclosure}

The authors report no conflicts of interest in this work.

\section{References}

1. Ehrich LC, Hansford B, Tennent L. Formal mentoring programs in education and other professions: A review of the literature. Educ Adm $Q$. 2013;40(4):518-540. 
2. Steiner JF, Curtis P, Lanphear BP, Vu KO, Main DS. Assessing the role of influential mentors in the research development of primary care fellows. Acad Med. 2004;79(9):865-872.

3. Palepu A, Friedman RH, Barnett RC, et al. Junior faculty members' mentoring relationships and their professional development in US medical schools. Acad Med. 1998;73(3):318-323.

4. Stamm M, Buddeberg-Fischer B. The impact of mentoring during postgraduate training on doctors' career success. Med Educ. 2011;45(5): 488-496

5. Kram KE. Mentoring at Work: Developmental relationships in organizational life. Lanham: University Press of America; 1988.

6. Sinclair P, Fitzgerald J E F, McDermott F D, Derbyshire L, Shalhoub J, ASiT Mentoring Collaboration. Mentoring during surgical training: consensus recommendations for mentoring programmes from the Association of Surgeons in Training. Int J Surg. 2014;12 (Suppl 3): S5-S8.

7. Ramanan RA, Taylor WC, Davis RB, Phillips RS. Mentoring matters. J Gen Intern Med. 2006;21(4):340-345.

8. Shanafelt TD, Bradley KA, Wipf JE, Back AL. Burnout and selfreported patient care in an internal medicine residency program. Ann Intern Med. 2002;136(5):358-367.

9. Collier VU, McCue JD, Markus A, Smith L. Stress in medical residency: status quo after a decade of reform? Ann Intern Med. 2002;136(5): 384-390.

10. Reuben DB. Depressive symptoms in medical house officers: effects of level of training and work rotation. Arch Intern Med. 1985;145(2): 286-288.

11. Kashiwagi DT, Varkey P, Cook DA. Mentoring programs for physicians in academic medicine: a systematic review. Acad Med. 2013;88(7):1 029-1037.

12. Paukert JL, Hsieh G. From medical student to Intern: Where are the role models? JAMA. 2001;285(21):2781.

13. Rose GL, Rukstalis MR, Schuckit MA. Informal mentoring between faculty and medical students. Acad Med. 2005;80:344-348

14. Ramaswami A, Dreher GF. The benefits associated with workplace mentoring relationships. In: Allen TD, Eby LT editors. The Blackwell handbook of mentoring: A multiple perspectives approach. Hoboken, NJ: Wiley-Blackwell; 2007:211-231.

15. Bland CJ, Taylor AL, Shollen SL, Weber-Main AM, Mulcahy PA. Faculty success through mentoring: A guide for mentors, mentees, and leaders. Lanham: Rowman \& Littlefield Publishers Inc.;2009.
16. Garmel GM. Mentoring medical students in academic emergency medicine. Acad Emerg Med. 2004;11(12):1351-1357.

17. International Working Party to Promote and Revitalise Academic Medicine. ICRAM (the International Campaign to Revitalise Academic Medicine): agenda setting. BMJ. 2004;329(7469):787-789.

18. Douglas CA. Formal Mentoring Programs in Organizations. An annotated bibliography. Greensboro, NC: Center for Creative Leadership; 1997.

19. Allen TD, Eby LT, Poteet ML, Lentz E, Lima L. Career benefits associated with mentoring for protégés: A meta-analysis. J Appl Psychol. 2004;89(1):127-136

20. Sambunjak D, Straus SE, Marušić A. Mentoring in academic medicine: a systematic review. JAMA. 2006;296(9):1103-1115.

21. Scott ES. Peer-to-peer mentoring: Teaching collegiality. Nurse Educ. 2005;30(2):52-56.

22. Buddeberg-Fischer B, Herta KD. Formal mentoring programmes for medical students and doctors - a review of the Medline literature. Med Teach. 2006;28(3):248-257.

23. Osborn LM, Sargent JR, Williams SD. Effects of time-in-clinic, clinic setting, and faculty supervision on the continuity clinic experience. Pediatrics. 1993;91(6):1089-1093.

24. Urish C. Ongoing competence through mentoring. OT Pract. 2004;9(3):10.

25. American Speech-Language-Hearing Association (ASHA). Clinical supervision in speech-language pathology. ASLA; 2008. Available from: https://www.lamar.edu/fine-arts-communication/_files/documents/speech-hearing/asha_report_supervision.pdf.

26. Kilminster SM, Jolly BC. Effective supervision in clinical practice settings: a literature review. Med Educ. 2000;34(10):827-840.

27. Straus SE, Chatur F, Taylor M. Issues in the mentor-mentee relationship in academic medicine: qualitative study. Acad Med. 2009;84(1):135-139.

28. Williams LL, Levine JB, Malhotra S, Holtzheimer P. The good-enough mentoring relationship. Acad Psychiatry. 2004;28:111-115.

29. Ehrich L, Hansford B, Ehrich JF. Mentoring across the professions: some issues and challenges. In: Millwater J, Beutal D, editors. Practical Experiences in Professional Education: A Transdisciplinary Approach. Brisbane: Post Pressed. 2011;93-113.

30. Hauer KE, Teherani A, Dechet A, Aagaard EM. Medical students' perceptions of mentoring: a focus-group analysis. Med Teach. 2005;27(8):732-734.

31. Sambunjak D, Straus SE, Marusic A. A systematic review of qualitative research on the meaning and characteristics of mentoring in academic medicine. J Gen Intern Med. 2010;25(1):72-78.
Advances in Medical Education and Practice

\section{Publish your work in this journal}

Advances in Medical Education and Practice is an international, peerreviewed, open access journal that aims to present and publish research on Medical Education covering medical, dental, nursing and allied health care professional education. The journal covers undergraduate education, postgraduate training and continuing medical education

\section{Dovepress}

including emerging trends and innovative models linking education, research, and health care services. The manuscript management system is completely online and includes a very quick and fair peer-review system. Visit http://www.dovepress.com/testimonials.php to read rea quotes from published authors. 